\title{
Low-Level Wind Forecast over the La Plata River Region with a Mesoscale Boundary-Layer Model Forced by Regional Operational Forecasts
}

\author{
L. Sraibman • G. J. Berri
}

Published online: 20 February 2009

(C) Springer Science+Business Media B.V. 2009

\section{Erratum to: Boundary-Layer Meteorol DOI 10.1007/s10546-009-9350-1}

An error occurs within the second paragraph of Section '2 Model Description'. In the text directly following Eq. 8, the sentence reading

"Equations 1-8 are solved from the top of the surface layer..." should read

"Equations 1-3 are solved from the top of the surface layer..."

The online version of the original article can be found under doi:10.1007/s10546-009-9350-1.

L. Sraibman $(\varangle) \cdot$ G. J. Berri

Departamento de Ciencias de la Atmósfera y los Océanos, Facultad de Ciencias Exactas y Naturales, Universidad de Buenos Aires, Buenos Aires, Argentina

e-mail: laurasra@at.fcen.uba.ar

G. J. Berri

e-mail: berri@at.fcen.uba.ar 